\title{
RESÚMENES DEL SEMINARIO DE INVESTIGACIÓN FILOSÓFICA (SIF)
}

El programa de Doctorado en Filosofía, Mención en Filosofía Moral y Política, de la Universidad de Chile ha creado la instancia académica de Seminario de Investigación Filosófica (SIF). Esta actividad promueve la presentación de los proyectos de investigación o trabajos de tesis realizados por los estudiantes de Magíster y Doctorado en Filosofía, para su posterior análisis y/o discusión en común con los asistentes. El propósito fundamental de esta instancia, es nutrir las investigaciones presentadas a partir de las opiniones y comentarios que los estudiantes y profesores del programa puedan entregar, tornándose así en un espacio de intercambio y diálogo efectivo. 


\section{SESIÓN SEGUNDO SEMESTRE 2014}

El pensamiento trágico y la libertad en los escritos de
juventud de Friedrich Nietzsche Carolina Llanos (Magíster en Filosofía)

El trabajo desarrollado en la presente investigación, tiene como objetivo fundamental profundizar y reflexionar sobre la relación que existe entre el pensamiento trágico y la libertad en el contexto de la obra nietzscheana de juventud. Para estos efectos, se tomará como punto de partida una delimitación y contextualización de lo que significa el pensamiento trágico como cosmovisión: el primer capítulo se concentrará en la referencia a un proceso en que se configura una interpretación trágica de la realidad en el ámbito de la filosofía y particularmente en el pensamiento de Nietzsche.

La segunda parte inicia con una búsqueda de los referentes griegos que se manifiestan en el pensamiento juvenil del autor, con la finalidad de reconstruir la noción de libertad. A partir del reconocimiento y profundización de los diversos temas y aspectos que aluden en distintos sentidos a la noción de libertad, se va distinguiendo entre un sentido metafísico y otro existencial, que finalmente conduce a la consideración política de la misma. De este modo, en el segundo capítulo se explicita la relación fundamental entre lo trágico y la libertad, donde el carácter agonal del juego aparece como elemento sustancial en dicha relación.

Finalmente, la libertad concebida desde lo trágico, así como también lo trágico desde la libertad, se ponen en relación con la crítica de la modernidad, donde tal época histórica es interpretada como hybris en cuanto en ella 
aparece trastocada la relación entre el ser humano y el límite Una de las consecuencias es que se encubre la noción auténtica de libertad, que en la perspectiva nietzscheana se vincula con un proceso de despliegue de la vida humana individual y colectiva, donde resulta fundamental el reconocimiento de la continuidad ontológica entre humanidad y naturaleza, así como también el replanteamiento de la formación y las metas de la cultura, todo esto en un horizonte de comprensión que valora desde un pesimismo de la fortaleza.

\section{Una mirada a la migración internacional en América Latina desde el concepto de libertad política en Hannah Arendt Luis Franco (Doctorado en Filosofía)}

Según el PNUD, cerca de 200 millones de personas viven por fuera de sus países de origen, expulsados o motivados por una mejor calidad de vida. Sin embargo, del creciente fenómeno migratorio no se desprende que se esté construyendo una Comunidad Universal, pues no solo la decisión migratoria en la mayoría de los casos es individual y esto implica la búsqueda de sus propios fines, sino que las fuerzas externas actúan con motivaciones ajenas a las humanas. Por esto, no es de extrañar que el deseo imperialista de las empresas no solo busque la conquista de nuevos mercados, sino la salida de ciudadanos de su propio país, pues el objetivo es encontrar individuos más solos, más vulnerables y por lo mismo más productivos, fruto de su desarraigo y posterior alienación. Tal vez no se repitan las 
condiciones que llevaron a Arendt a hablar del Totalitarismo como el fenómeno político del siglo XX dado en la Alemania Nazi y en la Rusia Estalinista, pero si es probable que estemos frente a sistemas seudo-totalitarios que hace que los hombres tras su lucha por la sobrevivencia se olviden de lo más elemental y a la vez sublime que tiene el ser humano, esto es, de la libertad política, traducida por Arendt como la posibilidad de actuar juntos en un espacio común de aparición.

\section{SESIÓN PRIMER SEMESTRE 2015}

\section{De las prácticas de muerte a la sobrevivencia: sobre una comprensión biopolítica de la Dictadura Militar y \\ Transición en Chile} Luna Follegati (Doctorado en Filosofía)

Desde la lectura biopolítica, el presente proyecto de investigación busca comprender la historia reciente de Chile en torno a la Dictadura Militar y la transición democrática. Apelando a una crítica sobre los discursos teóricos que posibilitaron la llegada de la democracia, nos sumergiremos en un análisis en torno a los principales ejes conceptuales que cimentaron los discursos comprensivos en torno al pasado democrático, abordando problemas como el de Soberanía, Violencia, Guerra, Estado de Excepción, Campo de Concentración, por mencionar algunos. Particularmente, sostenemos que durante la Dictadura Militar chilena se gestó un tipo de gubernamentalidad afincada en el conflicto bélico, y 
cimentada por las posibilidades de muerte de las personas. La síntesis del proceso se condice mediante un diagnóstico donde la muerte se vuelve tanto un espacio constitutivo como límite externo: la vida se vuelca hacia un umbral de sobrevivencia, donde los problemas del continuar vivo parecen traspasar los propios límites de la conservación hasta configurarse en una forma de vida, tanto desde los mecanismos explícitos del hacer morir (campos de concentración, tortura, y desaparición), como también de las figuras que posibilitan la precarización y economización extrema de la vida (ejemplificada en nuestro caso a partir de las reformas constitucionales, educacionales y previsionales a partir de 1980). En este sentido, nuestra propuesta de trabajo se estructura en torno al problema de la sobrevivencia, en relación a tres ejes: la producción de muerte sistemática; la economización y precarización de la vida entendida como práctica constitutiva del neoliberalismo; y la elaboración de una racionalidad política transicional que cimentó el despliegue democrático neoliberal a partir de la temática de los Derechos Humanos y proyecto democrático en tanto discurso de defensa de la vida. Los efectos de estas tres lecturas se configuran en una nueva gubernamentalidad bélica, cuyo origen se sitúa en la Dictadura Militar y su despliegue administrativo durante el período de la transición. Apelamos así a una nueva lectura en torno a los discursos comprensivos en relación al Golpe y democracia transicional, desde el registro biopolítico e histórico. 


\section{Lenguaje, acción y bien en G.E.M. Anscombe Andrés Gallardo (Doctorado en Filosofía)}

La filosofía moderna buscó el fundamento del conocimiento en el "yo" y en la "conciencia". Por lo mismo, dejó fuera del saber evidente todo lo exterior a ella, todo lo que no estaba en el dominio de lo inmediatamente evidente. La voluntad, en cuanto es parte de la conciencia, tuvo un lugar relevante y se concibió dentro de la filosofía de la subjetividad. Sin embargo, la acción humana en el mundo fue entendida como parte de los procesos corporales y, por lo tanto, separada y distinta de la conciencia. Esta concepción tuvo importantes consecuencias epistemológicas y éticas, pero sobre todo la de concebir la acción como algo derivado frente a la primacía del conocimiento.

Durante el siglo XX y, en la línea de la revolución del lenguaje producida por la obra tardía de Wittgenstein, la acción comenzó a ser objeto de estudio y comenzó a ser reformulada. Los nuevos análisis sobre el lenguaje de la acción vinieron a cuestionar los viejos temas de la filosofía de la voluntad. Siguiendo a Wittgenstein, su discípula G.E.M. Anscombe continuó su trabajo, desarrollando nuevos aspectos de lo que se puede llamar "filosofía de la acción" (o teoría de la acción). En nuestro trabajo nos propondremos saber si es posible hablar de una filosofía de Anscombe y cuáles son los aportes de ésta a la filosofía de la acción (propondremos que hay una filosofía). Junto con ello, estableceremos cómo se plantea su pensamiento frente a los problemas éticos heredados de la modernidad con nuevos instrumentos epistemológicos y metodológicos. 